\title{
Multi-walled carbon nanotubes packed cartridge for the solid-phase extraction of several phthalate esters from water samples and their determination by high performance liquid chromatography
}

\author{
Ya-Qi Cai, Gui-Bin Jiang*, Jing-Fu Liu, Qing-Xiang Zhou \\ Key Laboratory of Environmental Chemistry and Ecotoxicology, Research Center for Eco-Environmental Sciences, \\ Chinese Academy of Sciences, P.O. Box 2871, Beijing 100085, PR China
}

Received 16 April 2003; received in revised form 30 June 2003; accepted 5 August 2003

\begin{abstract}
Being suspected to have carcinogenic and estrogenic properties, the determination of phthalate esters in various environmental samples is very important for environmental risk assessment. In the present paper, a new solid-phase extraction system for HPLC determination of di-ethyl-phthalate, di-n-propyl-phthalate, di-iso-butyl-phthalate, and di-cyclohexyl-phthalate was developed. The four analytes were quantitatively adsorbed on multi-walled carbon nanotubes packed cartridge, then the analytes were quantitatively desorbed with acetonitrile, finally the analytes in acetonitrile eluate were determined by HPLC. Parameters influencing the extraction efficiency such as volume of sample solutions and eluent volume, were examined. Under the optimized conditions, detection limits of $0.18-0.86 \mathrm{ng} \mathrm{ml}^{-1}$ were achieved for four phthalate esters. The proposed method had been used to determine the four phthalate esters in tap water, river water, and sea water samples. No phthalate esters were found in the river water and sea water samples. For the case of tap water sample, di-ethyl-phthalate, di- $n$-propyl-phthalate, and di-cyclohexyl-phthalate were not found, only $2.0 \mathrm{ng} \mathrm{ml}^{-1}$ of di-iso-butyl-phthalate was found. The accuracy of the proposed method was tested by recovery measurements on spiked samples, the recoveries of $80.3-104.5 \%$ were obtained in most cases. (C) 2003 Elsevier B.V. All rights reserved.
\end{abstract}

Keywords: Multi-walled carbon nanotubes; Solid-phase extraction; HPLC; Phthalates; HPLC-DAD; Water samples

\section{Introduction}

Recently, various environmental chemicals that may exert some harmful effects to animals and humans have attracted great public attention. Phthalate esters are widely regarded as such chemicals and they are widely used as plasticizers and additives in many daily used products such as plastics, pesticides, paints and cosmetics, etc. They can be leached from the above mentioned products and find a way to various

\footnotetext{
* Corresponding author. Fax: +86-10-62923563.

E-mail address: gbjing@mail.rcees.ac.cn (G.-B. Jiang).
}

environmental matrices, and therefore, they are ubiquitous in various environmental matrices [1,2]. Being suspected to have carcinogenic and estrogenic properties [3-6], the determination of these compounds in various environmental samples is demanded urgently for environmental risk assessment. The very low concentration level of phthalate esters and the complex matrix of many environmental samples make sample preparation necessary for a reliable determination of these compounds prior to their determination.

So far, various methods such as liquid-liquid extraction (LLE) [7-9], solid-phase extraction (SPE) [10-14], and solid-phase microextraction (SPME) 
[15-20] have been employed as sample pretreatment procedures for the determination of phthalate esters. Among above mentioned sample pretreatment procedures, solid-phase extraction based on the use of different types of adsorbents such as $\mathrm{C}_{18}$ [7], $\mathrm{C}_{8}$ [14], PS-DVB [11-14], and hydroxylated PS-DVB polymers [12] is the most widely used one.

Carbon nanotubes (CNT) are novel carbon materials first found in 1991 by S. Iijima, they can be divided into single-walled carbon nanotubes (SWNTs) [21] and multi-walled carbon nanotubes (MWNTs) [22] according to the carbon atom layers in the wall of the nanotubes. Possessing many unique electronic, mechanical, chemical properties, high surface area, and excellent strength, carbon nanotubes have attracted great attention in recent years $[23,24]$ and have exhibited great potential in many important application fields such as hydrogen storage [25,26], quantum nanowires [27], catalyst supports [28,29], and chemical sensors [30,31], etc. In the report by Long and Yang [32], it is shown that multi-walled carbon nanotubes have very strong adsorption to dioxin and they can be expected to be an ideal adsorbent for dioxin removal with higher efficiency. Additionally, it is reported that the internal surface of carbon nanotubes interacts strongly with the enzyme proteins and the carbon nanotubes appear to act as a benign host to encapsulate protein molecules in their internal tube cavity [33]. The strong interaction between carbon nanotubes and dioxin or other molecules may be attributed to the unique structure of carbon nanotubes. The hexagonal arrays of carbon atoms in graphene sheets of carbon nanotubes' surface have strong interaction with the two benzene rings of dioxin. The facts mentioned above show that carbon nanotubes may have great analytical potential as effective solid-phase extraction adsorbent for some compounds. Recently, our group demonstrated, for the first time, that multi-walled carbon nanotubes can be used as effective adsorbents for solid-phase extraction of bisphenol, 4- $n$-nonylphenol and 4-tert-octylphenol from aqueous solution and they have been applied for the analysis of these three compounds in several real environmental samples [34]. In the present paper, we extended the analytical applications of multi-walled carbon nanotubes to four phthalate esters, di-ethyl-phthalate, di- $n$-propyl-phthalate, di-iso-butyl-phthalate, and di-cyclohexyl-phthalate. For this purpose, four analytes were extracted by the multi-walled carbon nanotubes packed cartridge from aqueous solutions. Then the four analytes retained on multi-walled carbon nanotubes were eluted with $5 \mathrm{ml}$ of acetonitrile. Finally the eluate was analyzed by high performance liquid chromatography. Parameters influencing the analytical performance, including sample volume and eluent volume have been studied. The analytical performance of the proposed method was evaluated by comparison with other methods that reported in literatures and has been applied for the analysis of water samples.

\section{Experimental}

\subsection{Apparatus, reagents, and water samples}

All reagents were of analytical-reagent grade and purified water by Milli-Q system was used throughout the experiments. Di-ethyl-phthalate was purchased from Beijing Chemicals Corporation (Beijing, China). Di-n-propyl-phthalate, di-iso-butyl-phthalate, and dicyclohexyl-phthalate were obtained from Acros Organics (NJ, USA). LC-grade methanol and acetonitrile were purchased from Scharlace Chemie SA, Barcelona, Spain. Standard stock solutions $(1000 \mu \mathrm{g}$ $\mathrm{ml}^{-1}$ ) containing these compounds were prepared in methanol and stored at $4{ }^{\circ} \mathrm{C}$. Working solutions were prepared daily by appropriate dilution of the stock solutions with water. Sodium hydroxide and hydrochloric acid were guarantee grade reagents (Beijing Chemicals Corporation).

Multi-walled carbon nanotubes with an average external diameter of 30-60 nm were kindly provided by Tsinghua-Nafine Nano-Powder Commercialization Engineering Center, Chemical Engineering Department of Tsinghua University, Beijing, China. The physical characterization of the nanotubes was examined using JEOL FEG-SEM (JSM-6301 F) scan electron microscopes with a resolution (SEI) $1.5 \mathrm{~nm}$ and the SEM image of the MWNTs at high magnification was described elsewhere [34]. Many multi-walled carbon nanotubes with general outer diameters of $30-60 \mathrm{~nm}$ can be observed. Other nanotubes with diameters beyond above range also exist. The length of nanotubes can not be measured since many nanotubes twist together and their both ends are not visible at the same time. The $\mathrm{N}_{2}$ adsorption isotherm at $77 \mathrm{~K}$ 
was gravimetrically determined using NOVA 1200 surface area analyzer after preevacuation of the nanotube samples at $373 \mathrm{~K}$ and $1 \mathrm{mPa}$ for $8 \mathrm{~h}$. The specific surface area of multi-walled carbon nanotubes was determined from the linear portion of the BET plots $\left(P / P_{0}=0.04-0.25\right)$ it is $131.74 \mathrm{~m}^{2} \mathrm{~g}^{-1}$.

To reduce the organic and inorganic contaminants, all beakers, calibrated flasks, and other glassware used in experiments were cleaned sequentially with tap water, neutral detergent, and tap water, then soaked in nitric acid $(1+1)$ for $48 \mathrm{~h}$ and cleaned with Mill Q purified water.

River water sample was collected from the Jingmi Canal. Seawater sample was collected from Bering and Chukchi sea at Chinese polar research vessel Xuelong during the First Chinese Arctic Research Expedition from July to September 1999. The collected water samples were filtered through a Millipore cellulose membrane with pore size $0.45 \mu \mathrm{m}$ immediately after sampling and maintained in glass containers, then stored at a temperature of $4{ }^{\circ} \mathrm{C}$.

The HPLC instrument used included a SCL-10Avp system controller (Shimadzu, Japan), a LC-10Atvp pump (Shimadzu, Japan), and a SPD-M10Avp diode array detector (DAD, Shimadzu, Japan) set at $226 \mathrm{~nm}$ wavelength for detection. A personal computer equipped with a Class-VP Workstation (Shimadzu, Japan) was used to acquire and process chromatographic data. Peak area was used as the analytical signal for determination. An Agilent Zorbax Eclipse $\mathrm{XDB}_{-} \mathrm{C}_{8}$ column $(150 \times 4.6 \mathrm{~mm}$, particle size $5 \mu \mathrm{m})$ was used as separation column. The mobile phase was a mixture of acetonitrile and water $(67: 33, \mathrm{v} / \mathrm{v})$ and its flow rate was set at $1 \mathrm{ml} \mathrm{min}{ }^{-1}$. Under these chromatographic conditions, baseline separation can be obtained within $16 \mathrm{~min}$ for four phthalate esters.

\subsection{Solid-phase extraction cartridge}

Multi-walled carbon nanotubes packed cartridge was prepared by modifying an Agilent ZORBAX SPE $\mathrm{C}_{18}$ (EC) cartridge ( $0.5 \mathrm{~g}, 6 \mathrm{ml}$, polypropylene), which was purchased from Agilent cooperation, USA. The $\mathrm{C}_{18}$ packing of the cartridge was evacuated, then $0.5 \mathrm{~g}$ multi-walled carbon nanotubes was packed in the cartridge. The polypropylene upper frit and lower frit were remained at each end of the cartridge to hold the carbon nanotubes packing in place. Next, the outlet tip of cartridge was connected to a model SHZ-3 (III) vacuum pump (Yuhua Instrument Co., Zhengzhou, Henan) and the inlet end of it was connected to a PTFE suction tube whose other end inserted into sample solution. Then, a solid-phase extraction system was ready for use. In order to reduce organic and inorganic contaminants, the entire SPE assembly was carefully washed with sufficient methanol and water.

\subsection{SPE procedure}

As a preconcentration step, the multi-walled carbon nanotubes packed cartridge was washed by $5 \mathrm{ml}$ of methanol and activated with $5 \mathrm{ml}$ of water. Then a known volume of purified water or sample water spiked with four analytes, di-ethyl-phthalate, di- $n$-propyl-phthalate, di-iso-butyl-phthalate, and dicyclohexyl-phthalate, was passed through the cartridge at a flow rate of $8 \mathrm{ml} \mathrm{min}{ }^{-1}$. After the sample solution had passed through, the cartridge was washed with $5 \mathrm{ml}$ of $10 \%$ metnanol aqueous solution to remove coadsorbed matrix materials from the cartridge. Then the analytes retained on the SPE packing was eluted with $5 \mathrm{ml}$ of acetonitrile. Finally $20 \mu \mathrm{l}$ of acetonitrile eluate was injected into the HPLC system for the HPLC determination. By using the acetonitrile standard solutions of four analytes, the external calibration curve can be acquired, then the concentration of four analytes in the eluate can be got. Finally the recoveries of four analytes at different conditions can be obtained by comparing the concentration of four analytes in the eluate with the spiked concentration levels.

\section{Results and discussion}

\subsection{Evaluation of solid-phase extraction sorbent}

To evaluate the analytical potential of multi-walled carbon nanotubes as SPE sorbent for di-ethyl-phthalate, di-n-propyl-phthalate, di-iso-butyl-phthalate, and dicyclohexyl-phthalate,. The parameters affecting the extraction efficiency of four analytes, such as the eluent volume and the sample volume were carefully investigated.

Since reversed high performance liquid chromatography was used, for convenience, only three solvents that are miscible with water, including 


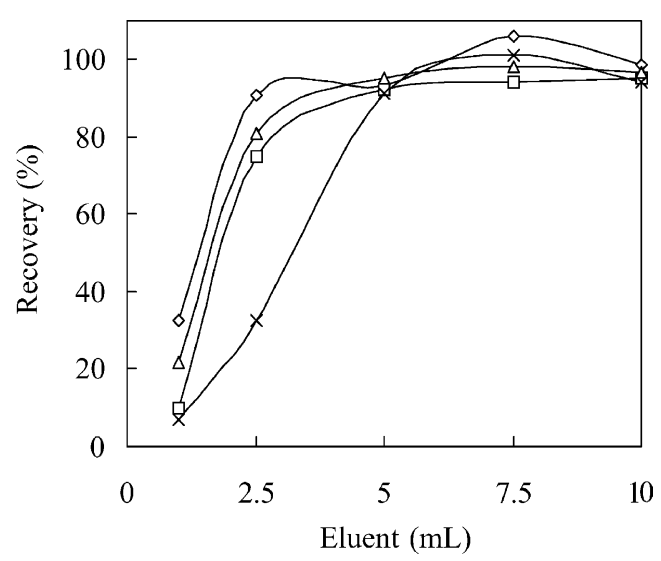

Fig. 1. Effect of volume of eluent acetonitrile on the recoveries of four analytes by using a multi-walled carbon nanotubes packed cartridge. $(\diamond)$ Di-ethyl-phthalate; $(\square)$ di- $n$-propyl-phthalate; $(\triangle)$ di-iso-butyl-phthalate; $(\times)$ di-cyclohexyl-phthalate. Volume of standard solutions: $1000 \mathrm{ml}$; concentration of four analytes: $20 \mathrm{ng} \mathrm{ml}^{-1}$; flow rate of sample solutions: $8 \mathrm{ml} \mathrm{min}^{-1}$. See text for the other experimental conditions.

methanol, acetonitrile, and acetone, were tested. Of the three solvents, it was found that acetonitrile was the most effective eluent for four analytes, and therefore it was accepted as an eluent. To find the required volume of acetonitrile to elute all four analytes from the cartridge, eluent volumes up to $10 \mathrm{ml}$ were tested with $1000 \mathrm{ml}$ of standard solutions of $20 \mathrm{ng} \mathrm{ml}^{-1}$ of four analytes, and the flow rate of sample solutions was set at $8 \mathrm{ml} \mathrm{min}^{-1}$, the results are shown in Fig. 1. The recoveries of 93.2-106.2\%, $92.1-95.0 \%, 95.1-98.2 \%$, and $91.5-101.1 \%$ could be achieved for di-ethyl-phthalate, di-n-propyl-phthalate, di-iso-butyl-phthalate, and di-cyclohexyl-phthalate, respectively, when the volume of acetonitrile was in the range of 5-10 $\mathrm{ml}$, which could be acceptable for the determination of trace pollutants in the ordinary environmental water samples. To get a high enrichment factor, $5 \mathrm{ml}$ of acetonitrile was adopted as the eluent. Although complete desorption made carryover be very minor, to obtain quantitative analytical result for the next extraction, the cartridge was washed further with another $3 \mathrm{ml}$ acetonitrile at the end of each extraction. In this way, the cartridge was immediately available for the next extraction.

In the solid-phase extraction system, the flow rate of the sample solution is one of the most important parameters, which not only affects the recoveries of analytes, but also controls the time of analysis. It was found that flow rates up to $8 \mathrm{ml} \mathrm{min}^{-1}$ (the maximum flow rate of our vacuum pump) for water sample loading on the cartridge had no effect on the recoveries of four analytes. Therefore, $8 \mathrm{ml} \mathrm{min}^{-1}$ was adopted as the flow rate of sample solutions.

To obtain reliable analytical results and a high concentration factor, it is very important to get satisfactory recoveries for all analytes in as large volume of sample solutions as possible. So it is necessary to obtain the breakthrough volumes in the solidphase extraction. In order to determine the breakthrough volumes, different volumes $(500,1000,1500$, 2000 , and $3000 \mathrm{ml}$ ) of river water were spiked with $20 \mu \mathrm{g}$ di-ethyl-phthalate, di-n-propyl-phthalate, diiso-butyl-phthalate, and di-cyclohexyl-phthalate. Following the experimental procedure, the recoveries of four analytes at different volumes were obtained. The effects of sample volumes on the recoveries of four analytes are shown in Fig. 2. The recoveries of $94.5-101.3 \%, 91.5-96.1 \%, 91.2-97.7 \%$, and

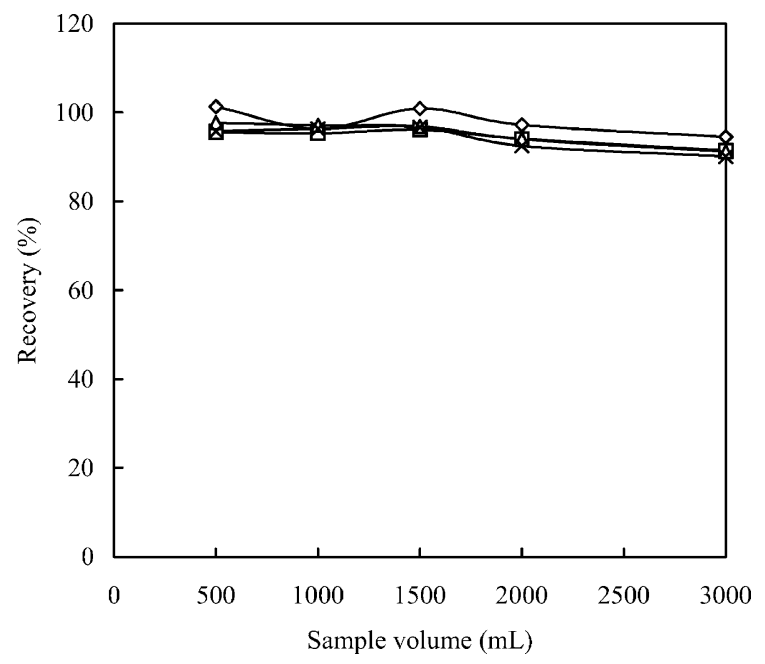

Fig. 2. Effect of volume of water sample solutions on the recoveries of four analytes by using a multi-walled carbon nanotubes packed cartridge. $(\diamond)$ Di-ethyl-phthalate; $(\square)$ di- $n$-propyl-phthalate; $(\triangle)$ di-iso-butyl-phthalate; $(\times)$ di-cyclohexyl-phthalate. Water sample solution: $20 \mu \mathrm{g}$ di-ethyl-phthalate, di-n-propyl-phthalate, di-iso-butyl-phthalate, and di-cyclohexyl-phthalate were dissolved in different volume of river water; volume of eluent acetonitrile: $5 \mathrm{ml}$; flow rate of sample solutions: $8 \mathrm{ml} \mathrm{min}^{-1}$. See text for the other experimental conditions. 
90.1-96.7\% were obtained for di-ethyl-phthalate, di- $n$-propyl-phthalate, di-iso-butyl-phthalate, and dicyclohexyl-phthalate, respectively, when the volumes of river water samples were under $3000 \mathrm{ml}$, which were acceptable in general analyses. In the analyses of several water samples, a sample volume of $1000 \mathrm{ml}$ was selected. Under these conditions, effective enrichment and matrix separation can be obtained for di-ethyl-phthalate, di- $n$-propyl-phthalate, di-isobutyl-phthalate, and di-cyclohexyl-phthalate.

\subsection{Comparison studies}

For comparative studies, the results obtained in this paper were compared with those of other reports. As mentioned in breakthrough volume experiment above, the recoveries of $94.5-101.3 \%$, $91.5-96.1 \%, 91.2-97.7 \%$, and $90.1-96.7 \%$ were obtained for di-ethyl-phthalate, di- $n$-propyl-phthalate, di-iso-butyl-phthalate, and di-cyclohexyl-phthalate, respectively, when the volumes of river water samples were under $3000 \mathrm{ml}$. In some cases, it appears that the recoveries obtained in the present work with river water samples are better than those obtained in some of other research work [12,13]. In report [12], both PS-DVB (Isolute 101) and hydroxylated PS-DVB (Isolute ENV+) were used for the preconcentration of several phthalate esters aqueous solution and recoveries obtained were all between 61 and $89 \%$. In report [13], another brand PS-DVB resin Lichrolut EN Bakerbond was used for the preconcentration of dibutylphthalate and dimethylphthalate in spiked wastewater samples at $50 \mathrm{ng} / \mathrm{ml}$ and recoveries were between 41 and $69 \%$. In other cases, it appears that the recoveries obtained in the present work are as good as those obtained by other researchers [7,11,14]. In report [7], $\mathrm{C}_{8}$ SPE cartridge was used for the preconcentration of several phthalate esters from $200 \mathrm{ml}$ of redistilled water spiked with $20 \mathrm{ng} / \mathrm{ml}$ concentration level and recoveries obtained were between 72 and 95\%. In Jara et al.'s [11] report, the ENV + SPE, a type of polystyrene adsorbent, was used for the preconcentration of butylbenzylphthalate and di-(2-ethylhexyl)phthalate from spiked tap water sample and recoveries obtained were between 99 and 104\%. In report [14], $\mathrm{C}_{8}$ SPE cartridge (ISOLUTE ${ }^{\circledR}$, IST, UK) and PS-DVB cartridge (ISOLUTE ENV $+{ }^{\circledR}$, IST, UK) were used for the preconcentration of several phthalate esters from surface water sample spiked at $1 \mathrm{ng} / \mathrm{ml}$ concentration level and recoveries obtained were between 90 and $98 \%$.

In respect to the extraction recoveries, above mentioned facts show that multi-walled carbon nanotubes were more effective than or as effective as some other commercially available SPE adsorbents such $\mathrm{C}_{18}, \mathrm{C}_{8}$, and PS-DVB for the solid-phase extraction of di-ethyl-phthalate, di- $n$-propyl-phthalate, di-iso-butyl-phthalate, and di-cyclohexyl-phthalate. Carbon nanotubes are hollow nanosize tubes that constitute a new structure of graphitic carbon consisting of one or several concentric tubules with a helically wound hexagonal honeycomb lattice. The reason why the multi-walled carbon nanotubes have stronger interaction with these analytes perhaps is that the hexagonal arrays of carbon atoms in graphene sheets in their structures may have strong interaction with the benzene ring in their structures.

\subsection{Analytical performance and application}

Under the selected conditions, the analytical performance of the proposed method was assessed with standard solutions and spiked river water samples, the results obtained with standard solutions are given in Table 1. There is a linear correlation between peak area and concentration of four phthalate esters from 2 to $100 \mathrm{ng} \mathrm{ml}^{-1}$. The slopes of calibration curves of four analytes based on standard solutions and spiked river water solutions tested were almost independent of the matrix of the samples. The limits of detection with an extracting $1000 \mathrm{ml}$ of water sample are calculated as three times the standard deviation of five replicate runs of procedure blanks.

The proposed method had been applied to the analysis of tap water, river water, and sea water

Table 1

Linear range, correlation coefficients, and detection limits

\begin{tabular}{llll}
\hline Compound & $\begin{array}{l}\text { Linear range } \\
\left(\mathrm{ng} \mathrm{ml}^{-1}\right)\end{array}$ & $R$ & $\begin{array}{l}\text { LOD } \\
\left(\mathrm{ng} \mathrm{ml}^{-1}\right)\end{array}$ \\
\hline Di-ethyl-phthalate & $2.0-100$ & 0.9997 & 0.18 \\
Di- $n$-propyl-phthalate & $2.0-100$ & 0.9995 & 0.23 \\
Di- $i$ so-butyl-phthalate & $2.0-100$ & 0.9995 & 0.48 \\
Di-cyclohexyl-phthalate & $2.0-100$ & 0.9996 & 0.86 \\
\hline
\end{tabular}


Table 2

Determination and recoveries of four analytes spiked water samples

\begin{tabular}{|c|c|c|c|}
\hline Water sample & Added (ng ml ${ }^{-1}$ ) & Found $^{\mathrm{a}}\left(\mathrm{ng} \mathrm{ml}^{-1}\right)$ & Recovery $^{\mathrm{b}}(\%)$ \\
\hline \multicolumn{4}{|l|}{ Tap water } \\
\hline \multirow[t]{3}{*}{ Di-ethyl-phthalate } & - & nd & - \\
\hline & 10.0 & 8.92 & $89.2 \pm 1.2$ \\
\hline & 20.0 & 19.0 & $95.0 \pm 1.3$ \\
\hline \multirow[t]{3}{*}{ Di- $n$-propyl-phthalate } & - & nd & - \\
\hline & 10.0 & 9.02 & $90.2 \pm 2.0$ \\
\hline & 20.0 & 19.3 & $96.5 \pm 9.9$ \\
\hline \multirow[t]{3}{*}{ Di-iso-butyl-phthalate } & - & 2.0 & - \\
\hline & 10.0 & 11.3 & $93.0 \pm 2.8$ \\
\hline & 20.0 & 22.0 & $100.0 \pm 8.2$ \\
\hline \multirow[t]{3}{*}{ Di-cyclohexyl-phthalate } & - & nd & - \\
\hline & 10.0 & 10.1 & $101.0 \pm 10.4$ \\
\hline & 20.0 & 18.4 & $92.0 \pm 7.6$ \\
\hline \multicolumn{4}{|l|}{ River water } \\
\hline \multirow[t]{3}{*}{ Di-ethyl-phthalate } & - & nd & - \\
\hline & 10.0 & 8.22 & $82.2 \pm 6.9$ \\
\hline & 20.0 & 18.3 & $91.5 \pm 1.5$ \\
\hline \multirow[t]{3}{*}{ Di- $n$-propyl-phthalate } & - & nd & - \\
\hline & 10.0 & 8.45 & $84.5 \pm 4.4$ \\
\hline & 20.0 & 19.3 & $96.5 \pm 7.9$ \\
\hline \multirow[t]{3}{*}{ Di-iso-butyl-phthalate } & - & nd & - \\
\hline & 10.0 & 9.35 & $93.5 \pm 4.9$ \\
\hline & 20.0 & 18.4 & $92.0 \pm 5.1$ \\
\hline \multirow[t]{3}{*}{ Di-cyclohexyl-phthalate } & - & nd & - \\
\hline & 10.0 & 6.84 & $68.4 \pm 7.9$ \\
\hline & 20.0 & 18.9 & $94.5 \pm 4.4$ \\
\hline \multicolumn{4}{|l|}{ Sea water } \\
\hline \multirow[t]{3}{*}{ Di-ethyl-phthalate } & - & nd & - \\
\hline & 10.0 & 8.33 & $83.3 \pm 1.4$ \\
\hline & 20.0 & 18.1 & $90.5 \pm 2.4$ \\
\hline \multirow[t]{3}{*}{ Di-n-propyl-phthalate } & - & nd & - \\
\hline & 10.0 & 8.03 & $80.3 \pm 2.2$ \\
\hline & 20.0 & 18.9 & $94.5 \pm 1.9$ \\
\hline \multirow[t]{3}{*}{ Di-iso-butyl-phthalate } & - & nd & - \\
\hline & 10.0 & 9.46 & $94.6 \pm 3.7$ \\
\hline & 20.0 & 17.4 & $87.0 \pm 1.6$ \\
\hline \multirow[t]{3}{*}{ Di-cyclohexyl-phthalate } & - & nd & - \\
\hline & 10.0 & 9.66 & $96.6 \pm 8.2$ \\
\hline & 20.0 & 20.9 & $104.5 \pm 5.0$ \\
\hline
\end{tabular}

${ }^{a}$ Mean for five determinations.

${ }^{\mathrm{b}}$ Mean and standard deviation for five determinations; nd: not detected.

samples and the results are shown in Table 2. Recovery tests were carried out with standard phthalate ester mixtures spiked water samples and the results are also presented in Table 2. No di-ethyl-phthalate, di- $n$-propyl-phthalate, di-iso-butyl-phthalate, and dicyclohexyl-phthalate were found in the river water and sea water samples. For the case of tap water samples, di-ethyl-phthalate, di- $n$-propyl-phthalate, and di-cyclohexyl-phthalate were not found, only $2.0 \mathrm{ng} \mathrm{ml}^{-1}$ of di-iso-butyl-phthalate was found. It is observed from Table 2 that the recoveries are satisfactory in most of situations. The chromatograms of a tap water sample and its spiked standard solution are shown in Fig. 3. 


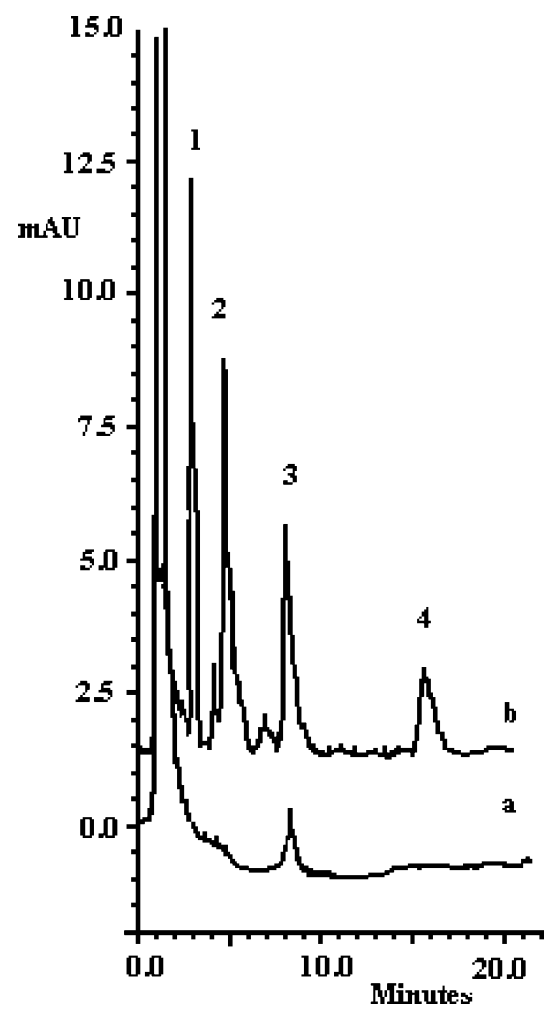

Fig. 3. LC chromatograms of tap water samples: (a) tap water sample, (b) tap water sample spiked with $20 \mathrm{ng} \mathrm{ml}^{-1}$ of each compound. (1) Di-ethyl-phthalate, (2) di- $n$-propyl-phthalate, (3) di-iso-butyl-phthalate, and (4) di-cyclohexyl-phthalate. Volume of water sample solutions: $1000 \mathrm{ml}$; flow rate of sample solutions: $8 \mathrm{ml} \mathrm{min}{ }^{-1}$; volume of eluent acetonitrile: $5 \mathrm{ml}$. See text for the other experimental conditions.

\section{Conclusions}

From the foregoing, we can come to the conclusion that that multi-walled carbon nanotubes possess remarkable potential for solid-phase extraction of trace di-ethyl-phthalate, di- $n$-propyl-phthalate, di-iso-butyl-phthalate, and di-cyclohexyl-phthalate from aqueous solution. The recoveries of SPE using multi-walled carbon nanotubes cartridge were compared with several commercial SPE adsorbents such as $\mathrm{C}_{18}, \mathrm{C}_{8}$, and PS-DVB, the results showed that multi-walled carbon nanotubes were more effective than or as effective as these adsorbents for the solid-phase extraction of the four analytes. Based on the experimental results, a simple and reliable method was developed for the solid-phase extraction and HPLC determination of four analytes in tap water, river water, and sea water samples. It takes about $2 \mathrm{~h}$ to complete a sample determination. Under the optimized conditions, detection limits of $0.18-0.86 \mathrm{ng} \mathrm{ml}^{-1}$ were achieved for four phthalate esters. The accuracy of the proposed method was tested by recovery measurements on spiked samples, the recoveries of $80.3-104.5 \%$ were obtained in most cases. In conclusion, it is shown that as promising sorbents, multi-walled carbon nanotubes have great potential for solid-phase extraction of some pollutants. It is expected that multi-walled carbon nanotubes can be potentially applied to the enrichment and determination of many other pollutants. Work is in progress in this direction.

\section{Acknowledgements}

This work was jointly supported by the National Natural Science Foundation of China, the National High Technology Project and the Chinese Academy of Sciences (KZCX2-410).

\section{References}

[1] I. Steiner, L. Scharf, F. Fiala, J. Washuttl, Food Addit. Contam. 15 (1998) 812.

[2] M. Castillo, A. Oubina, D. Barcelo, Environ. Sci. Technol. 32 (1998) 225.

[3] C.A. Harris, P. Henttu, M.G. Parker, J.P. Sumpter, Environ. Health Perspect. 105 (1997) 802.

[4] L.H. Keith, Environmental Endocrine Disruptors-Handbook of Property Data, Wiley/Interscience, New York, 1997.

[5] C.R. Tyler, S. Jobling, J.P. Sumpter, Crit. Rev. Toxicol. 28 (1998) 319.

[6] J. Toppari, J.C. Larsen, P. Christiansen, A. Giwercman, P. Grandjean, L.J. Guillette, B. Jegou, T.K. Jensen, P. Jouannet, N. Keiding, K. Leffers, J.A. McLachlan, O. Meyer, J. Muller, E. Rajpert De Meyts, T. Scheike, R. Sharpe, J. Sumpter, N.E. Skakkebaek, Environ. Health Perspect. 104 (1996) 741.

[7] K. Holadova, J. Hajslova, Int. J. Environ. Anal. Chem. 59 (1995) 43-57.

[8] A. Yasuhara, H. Shiraishi, M. Nishikawa, T. Yamamoto, T. Uehiro, O. Nakasugi, T. Okumura, K. Kenmotsu, H. Fukui, M. Nagase, Y. Ono, Y. Kawagoshi, K. Baba, Y. Noma, J. Chromatogr. A 774 (1997) 321.

[9] K. Kambia, T. Dine, B. Gressier, A.-F. Germe, M. Luyckx, C. Brunet, L. Michaud, F. Gottrand, J. Chromatogr. B 755 (2001) 297-303. 
[10] S. Jobling, T. Reynolds, R. White, M.G. Parker, J.P. Sumpter, Environ. Health Perspect. 103 (1995) 582.

[11] S. Jara, C. Lysebo, T. Greinbrokk, E. Lundanes, Anal. Chim. Acta 407 (2000) 165.

[12] S. Jonsson, H. Borén, J. Chromatogr. A 963 (2002) 393-400.

[13] M. Castillo, A. Oubiña, D. Barceló, Environ. Sci. Technol. 32 (1998) 2180-2184.

[14] M.L. Davi, M. Liboni, M.G. Malfatto, Int. J. Environ. Anal. Chem. 74 (1999) 155-166.

[15] A. Penalver, E. Pocurull, F. Borrull, R.M. Marce, J. Chromatogr. A 872 (2000) 191.

[16] A. Penalver, E. Pocurull, F. Borrull, R.M. Marce, J. Chromatogr. A 922 (2001) 377.

[17] G. Prokupkova, K. Holadova, J. Poustka, J. Hajslova, Anal. Chim. Acta 457 (2002) 211.

[18] M.T. Kelly, M. Larroque, J. Chromatogr. A 841 (1999) 177.

[19] M. Moder, P. Popp, J. Pawliszyn, J. Microcol. Sep. 10 (1998) 225.

[20] Y. Saito, Y. Nakao, M. Imaizumi, Y. Morishima, Y. Hiso, K. Jinno, Anal. Bioanal. Chem. 373 (2002) 81-86.

[21] S. Iijima, Nature (London) 354 (1991) 56-58.

[22] S. Iijima, T. Ichihashi, Nature (London) 363 (1993) 603-605.

[23] Z.F. Ren, Z.P. Huang, J.W. Xu, J.H. Wang, P. Bush, M.P. Siegal, P.N. Provencio, Science 282 (1998) 1105-1107.
[24] S.S. Wong, E. Joselevich, A.T. Wooley, C.L. Cheung, C.M. Lieber, Nature (London) 394 (1998) 52-55.

[25] A.C. Dillon, K.M. Jones, T.A. Bekkedahl, C.H. Kiang, D.S. Bethune, M.J. Heben, Nature (London) 386 (1997) 377-379.

[26] C. Liu, Y.Y. Fan, M. Liu, H.T. Cong, H.M. Cheng, M.S. Dresselhaus, Science 286 (1999) 1127-1129.

[27] S.J. Tans, M.H. Devoret, H. Dai, A. Thess, R.E. Smalley, L.J. Geerligs, C. Dekker, Nature (London) 286 (1997) 474-477.

[28] J.M. Planeix, N. Coustel, B. Coq, V. Brotons, P.S. Kumbhar, R. Dutartre, P. Geneste, P. Bernier, P.M. Ajayan, J. Am. Chem. Soc. 116 (1994) 7935-7935.

[29] G. Chen, B.B. Lakshmi, E.R. Fisher, C.R. Martin, Nature (London) 393 (1998) 346-349.

[30] J. Kong, N.R. Franklin, C. Zhou, M.G. Chapline, S. Peng, K. Cho, H. Dai, Science 287 (2000) 622-625.

[31] H. Luo, Z. Shi, N. Li, Z. Gu, Q. Zhuang, Anal. Chem. 73 (2001) 915-920.

[32] R.Q. Long, R.T. Yang, J. Am. Chem. Soc. 123 (2001) 20582059.

[33] J.J. Davis, M.L.H. Green, H.A.O. Hill, Y.C. Keung, P.J. Sadler, J. Sloan, A.V. Xavier, S.C. Tsang, Inorg. Chim. Acta 272 (1998) 261-266.

[34] Y.Q. Cai, G.B. Jiang, J.F. Liu, Q.X. Zhou, Anal. Chem. 75 (2003) 2517-2521. 